\title{
ALTERAÇÕES DOS NUTRIENTES NO SOLO E NAS PLANTAS EM CONSÓRCIO DE EUCALIPTO E ACÁCIA NEGRA(1)
}

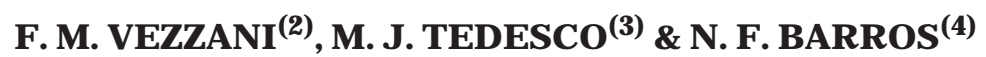

\begin{abstract}
RESUMO
O consórcio de eucalipto e acácia negra pode trazer benefícios ecológicos e econômicos, tendo em vista a diversidade ambiental e redução dos custos com adubação nitrogenada. Este trabal ho teve o objetivo de quantificar os nutrientes no solo e nas plantas e avaliar o crescimento e a produção de eucalipto em consórcio com acácia negra. Foram estudados sistemas de cultivo simples e consorciado de Eucalyptus saligna (Smith) e Acacia mearnsii (De Wild.), com 45 meses de idade, em Argi ssolo Vermelho-Amarelo, no estado do R io Grande do Sul. 0 espaçamento foi de 4,0 x 1,5 m e, no consórcio, as espécies foram plantadas em fileiras alternadas. Quantificaram-se $\mathrm{N}$ total, $\mathrm{P}, \mathrm{K}, \mathrm{Ca}, \mathrm{Mg}$, Al e matéria orgânica no solo e N total, P, K, Ca e Mg nas plantas. Avaliaram-se altura e diâmetro das árvores, bem como o volume de madeira produzido. As amostras de solo foram coletadas nas profundidades de 0-5, 5-10, $10-20$ e 20-40 cm. Os resultados demonstraram maior teor de matéria orgânica e nitrogênio total no solo do consórcio em relação ao eucalipto simples. Solo sob cultivo simples de acácia mostrou maior teor de $\mathrm{K}$, Ca e Mg que nos povoamentos em que o eucalipto estava presente. Plantas de eucalipto consorciado absorveram mais nitrogênio (22\%) do que as do cultivo si mples. O volume total de madeira no consórcio não diferiu do cultivo simples de eucalipto, embora o eucalipto tenha contribuído com $64 \%$ da produção do consórcio. 0 consórcio beneficiou a nutrição de nitrogênio do eucalipto e aumentou o estoque de nitrogênio no ecossistema, enquanto manteve a produção total de madeira.
\end{abstract}

Termos de indexação: Eucal yptus saligna, Acacia mearnsii , produção de madeira, absorção, estoque de nutrientes.

(1) Parte da Tese de Mestrado, apresentada pelo primeiro autor no Curso de Pós-Graduação em Ciência do Solo da Universidade Federal do Rio Grande do Sul - UFRGS, Porto Alegre (RS). Recebido para publicação em janei ro de 2000 e aprovado em setembro de 2000.

(2) Doutorando do Curso de Pós-Graduação em Ciência do Solo da Universidade F ederal do Rio Grande do Sul - UFRGS. CEP 90470001 Porto Alegre (RS). E-mail: vezzani@conex.com.br

(3) Professor titular do Departamento de Solos da UFRGS, CEP 90470-111 Porto Alegre (RS).

(4) Professor Titular do Departamento de Solos da Universidade Federal de Viçosa - UFV. CEP 36571-000 Viçosa (MG). Bolsista CNPq. 


\title{
SUMMARY: EFFECT OF MIXED PLANTATION OF Eucalyptus saligna AND Acacia mearnsii ON SOIL AND PLANT NUTRIENT CONTENT
}

\begin{abstract}
Mixed plantations of eucalypt and acacia can be beneficial from both the ecological and economic viewpoints, as they increase the biological diversity and reduce the costs of nitrogen fertilization. This trial had theobjectiveto evaluatethe effect of mi xed plantations of Eucalyptus saligna (Smith) and Acacia mearnsii (De Wild) on soil and stand characteristics. Theexperiment was carried out on a Red Yellow Latosol, in the state of Rio Grande do Sul, Brazil, and the treatment consisted of pure and mixed stands of the two species. The spacing was of 4 by $1,5 \mathrm{~m}$, and in the mixed stand the species were planted in alternate rows. The evaluati ons were performed when the stands were 45 months old. The trees were measured for diameter and height for volume estimation, the biomass of the aboveground components was determined and tissue samples taken for chemical analyses. Soil samples were col lected from 0-5; 5-10; $10-20$, and 20-40 cm depth. Total stem volume did not differ between mixed and eucalypt pureplantations. In the mi xed plantation, $64 \%$ of the total volume was provided by theeucalypt trees. The eucalypt trees in the mixed stands accumulated more(22\%) nitrogen than in thepurestands. Soil organic matter, total nitrogen was higher in the mixed than in the eucalypt pure stand. Soil under the pure stands of Acacia had higher basecontent than thosewhereeucalypt was present dueto eucalypt higher biomass production and nutrient accumulation. Mixed plantation improves eucalypt nitrogen nutrition and increases the nitrogen pools of the ecosystem while maintaining total wood production.
\end{abstract}

Index terms: Eucalyptus saligna, Acacia mearnsii, wood production, nutrient accumulation.

\section{NTRODUÇÃO}

NoRioGrande do Sul, o eucal ipto ea acácia negra são as principais espécies florestais cultivadas. A grande importância destas espécies está no uso em florestamento, com finalidade energética, fabricação de celulose e extração de tanino da casca da acácia negra. O cultivo de ambas as espécies no estado é feito em sistema plantio simples.

Plantios florestais consorciados podem ser mais produtivos que plantios simples (DeBell \& Harrington, 1993). N o consórcio, as árvores de cada espécie apresentam diferenças no crescimento fenológico, na conformação da copa, no sistema radicular ena exigência nutricional. N esta situação, as plantas de diferentes espécies podem complementar-se na captação de radiação solar, de água edenutrientes, resultando numa movimentação diferenciada de nutrientes no solo em comparação com um plantio simples.

O movimento de nutrientes nos povoamentos florestais se dá com a sua absorção pelas plantas em camadas mais profundas do sol o e o seu retorno à superfície pela lavagem da parte aérea e pel o ciclo biogeoquímico, liberando nutrientes do material vegetal depositado na superfície do solo, por meio da decomposição microbiana. A exsudação de substâncias pelas raízes também pode ser distinta, o que propicia maior diversidade e atividade dos mi crorganismos do solo, afetando a decomposição e a liberação de nutrientes da serapilheira. Em consórcio, a utilização dos recursos do meio é maior, conforme as diferenças entreas espécies, imprimindo maior efeito sobre o solo.

Florestas de eucalipto mostram alta demanda por nutrientes, principalmente nitrogênio, até à formação da copa, sendo todo nutriente absorvido do solo. Depois da copa estabelecida, a ciclagem de nutrientes da serapilheira para o solo torna- se a via mais importante de fornecimento de nutrientes para a floresta (Novais et al., 1990). O eucali pto pode ser favorecido quando cultivado em consórcio com uma leguminosa arbórea, que tenha capacidade de fixar simbioticamente nitrogênio atmosférico.

$\mathrm{Na}$ fase inicial de desenvolvimento da floresta (atéà formação da copa), o beneficio do consórcio para o eucal i pto dar-se-ia pelo incremento de nitrogênio aosolo, considerandoa liberação destenutrientepela decomposição de fol has e galhos descartados pela leguminosa, exsudação de substâncias orgânicas e decomposição das raízes.

$\mathrm{Na}$ fase posterior (após a formação da copa), a leguminosa aceleraria a ciclagem de nutrientes da serapilheira, pela redução da relação $\mathrm{C}: \mathrm{N}$ do material depositado sob o povoamento, estimulando a ação dos microrganismos decompositores e a conseqüente liberação de nutrientes. Plantas de eucalipto consorciadas com espécies leguminosas arbóreas, tais como Acacia e Albizia, têm sido avaliadas (DeBell et al., 1985; DeBell et al., 1987; DeBell et 
al., 1989) e parecem ser promissoras fontes alternativas de nitrogênio para a cultura do eucalipto, já que os custos, energético e financeiro, da adubação nitrogenada são altos.

Considerando a grande importância do eucalipto e da acácia negra para o Rio Grande do Sul, o consórcio de ambas as espécies podetrazer benefícios ecológicos, em razão da maior diversidade vegetal e da biota edáfica, além da melhor utilização dos recursos do ambiente. O benefício econômico decorre da possi bilidade de redução nos custos com adubação nitrogenada para o eucalipto. Estes benefícios do cultivo consorciado possuem potencial de elevar a produtividade e podem ser importantes para uma produção mais competitiva de madeira.

O objetivo deste trabalho foi determinar o teor de nutrientes no solo, sua absorção pelas plantas ea produção de madeira em sistemas de cultivo simples e em consórcio de eucal ipto e acácia negra.

\section{MATE RIAL E MÉTODOS}

A pesquisa foi real izada no HortoF lorestal Santa Rita, pertencente à empresa de Celulose e Papel Riocell S.A., no município de Minas do Leão, estado do Rio Grande do Sul, na região fisiográfica da Depressão Central. O solo da área experimental foi classificado como Argissolo Vermel ho-Amarelo, tendo o campo nativo como vegetação original .

O preparo do sol o foi feito com escarificador com três hastes, na linha de plantio. A adubação consistiu da aplicação de $300 \mathrm{~kg} \mathrm{ha}^{-1}$ de adubo que continha $67 \%$ de fosfato de Gafsa e $33 \%$ de superfosfato triplo, em sulco central feito pelo escarificador à profundidade de 15 a $25 \mathrm{~cm}$. Após seis meses do plantio, feito em agosto de 1991, aplicaram-se $100 \mathrm{~kg} \mathrm{ha}^{-1}$ da fórmula 20-0-20, a lanço, na linha das árvores. Os tratos culturais constaram da aplicação do herbicida glifosate na concentração de 1,5\%, na entrelinha das árvores, até os povoamentos completarem um ano de idade.

Os tratamentos consistiram no cultivo simples e noconsorciado deEucalyptus saligna (Smith) eAcacia mearnsi i (DeWild.), em espaçamento de 4,0 x 1,5 m (1.667 árvores por hectare). Notratamento referente ao consórcio, as espécies foram plantadas em fileiras alternadas, compondo um povoamento misto na proporção de 1:1. O delineamento experimental utilizado foi de blocos casualizados, com três repetições. A área de cada repetição foi de $540 \mathrm{~m}^{2}$, abrangendo, aproximadamente, 90 árvores.

\section{Avaliação do solo}

A amostragem do solo foi feita em cinco épocas: junho, setembro e dezembro de 1995; abril e julho de 1996. Em cada repeti ção, uma amostra composta, obtida de seis subamostras, foi coletada às profundidades de $0-5,5-10,10-20$ e $20-40 \mathrm{~cm}$. Os nutrientes determinados foram nitrogênio total (Kjeldahl); fósforo e potássio (Mehlich-1); cálcio, magnésio e alumínio trocáveis $\left(\mathrm{KCl} \mathrm{mol} \mathrm{L}^{-1}\right)$, e matéria orgânica. Utilizou-se o método descrito por Tedesco et al. (1995).

\section{Avaliação das plantas e da produção de madeira}

Aos 45 meses do plantio, efetuou-se a sel eção de uma árvore por repetição, que representava a média de altura, diâmetro, forma e arquitetura de copa. Todas as fol has e gal hos das árvores selecionadas foram destacados e pesados separadamente. Uma amostra, de aproximadamente 500 gramas de cada fração, foi separada para as análises químicas, que consistiram na determinação de nitrogênio total, fósforo, potássio, cálcioemagnésio, segundo o método de Tedesco et al. (1995).

O diâmetro à altura de $1,30 \mathrm{~m}$ do nível do solo (diâmetroà altura do peito- DAP) ea altura detodas as árvores no interior de cada uma das repetições foram medidos com auxílio de uma suta finlandesa e de um hipsômetro de Blume-Leiss. As alturas das árvores inclinadas e bifurcadas foram estimadas por meio de um model o de rel ação hipsométrica (rel ação altura/diâmetro). O volume de madeira foi determinado pelas equações descritas por Finger (1992).

\section{RESULTADOS E DISCUSSÃO}

\section{Atributos do solo}

Os teores de matéria orgânica no solo, nos diferentes tratamentos e em profundidade, são mostrados no quadro 1 . O teor de matéria orgânica nos primeiros centímetros de solo é maior em todos os tratamentos, em razão do acúmulo e da decomposição da serapilheira formada sob os povoamentos. A velocidade de decomposição do material vegetal decada tratamento foi avaliada por Vezzani et al. (1999) e os resultados demonstraram que o material de acácia teve maior decomposição em relação ao do eucalipto, no mesmo período de tempo. Tal comportamentoresultou em maior acúmulo de matéria orgânica no solo dos tratamentos com acácia (consórcio e acácia simples), tanto em superfície como em camadas mais profundas do solo. Os valores indicam uma superioridade de $4.000 \mathrm{~kg} \mathrm{ha}^{-1}$ de matéria orgânica no tratamento com consórcio, em relação ao tratamento com eucalipto simples, nos $10 \mathrm{~cm}$ superficiais do solo (Quadro 1).

Os teores de alumínio trocável no solo foram menores notratamento com acácia si mples, em todas as profundidades (Quadro 2). Dados de $\mathrm{pH}$ do solo 
colaboram para explicar este fato, uma vez que em sol os mais ácidos o teor de al umínio trocável émaior. O tratamento com acácia simples apresentou maior índice de $\mathrm{pH}$ do solo, em relação aos demais tratamentos (Quadro 2). Todavia, apesar de o pH do solo apresentar diferença estatística entre os tratamentos, os valores são muito próximos, não justificando o comportamento observado para o alumínio. No caso do tratamento de acácia simples, o efeito complexante da matéria orgânica com o alumínio(Salet, 1998) foi ofator preponderante para explicar o menor teor de alumínio trocável, pois houve diminuição do teor de matéria orgânica com a profundidade e concomitante aumento do teor de alumínio trocável (Quadros 1 e 2).

Os teores de fósforo no solo (Quadro 3) não diferiram entre os tratamentos, demonstrando que não houve benefício para o ciclo biogeoquími co deste nutriente com a presença de acácia. Além disso, a concentração de fósforo no tecido das plantas foi muito baixa (Quadro 5), em relação aos demais nutrientes, demonstrando pequeno potencial para ciclagem.

Quadro 1. Teores de matéria orgânica no solo (médias de cinco épocas de amostragem e três repetições)

\begin{tabular}{cccc}
\hline Profundidade & Eu x Ac & Eucalipto & Acácia \\
\hline $\mathrm{cm}$ & \multicolumn{3}{c}{$\mathrm{g} \mathrm{dm}^{-3}$} \\
$0-5$ & $32 \mathrm{~A} \mathrm{a}$ & $27 \mathrm{~B} \mathrm{a}$ & $33 \mathrm{~A} \mathrm{a}$ \\
$5-10$ & $26 \mathrm{~A} \mathrm{~b}$ & $23 \mathrm{~B} \mathrm{~b}$ & $26 \mathrm{~A} \mathrm{~b}$ \\
$10-20$ & $24 \mathrm{~A} \mathrm{~b}$ & $20 \mathrm{~B} \mathrm{C}$ & $23 \mathrm{~A} \mathrm{c}$ \\
$20-40$ & $21 \mathrm{~A} \mathrm{C}$ & $18 \mathrm{~B} \mathrm{~d}$ & $20 \mathrm{~A} \mathrm{~d}$
\end{tabular}

Médias com letras maiúsculas distintas, entre tratamentos, e minúsculas distintas, entre profundidades, diferem entre si (Duncan, 5\%).

Quadro 2. Índice de pH e teores de alumínio trocável no solo (médias de cinco épocas de amostragem e três repetições)

\begin{tabular}{cccc}
\hline Profundidade & Eu x Ac & Eucalipto & Acácia \\
\hline$(\mathrm{cm})$ & \multicolumn{4}{c}{$\mathrm{pH}$} \\
$0-20$ & $4,4 \mathrm{~B}$ & $4,3 \mathrm{C}$ & $4,6 \mathrm{~A}$ \\
\multicolumn{4}{c}{ Alumínio $\left(\mathrm{cmol}_{\mathrm{c}} \mathrm{dm}^{-3}\right)$} \\
$0-5$ & $1,96 \mathrm{~A} \mathrm{C}$ & $2,30 \mathrm{~A} \mathrm{~b}$ & $0,99 \mathrm{~B} \mathrm{c}$ \\
$5-10$ & $2,20 \mathrm{~A} \mathrm{C}$ & $2,48 \mathrm{~A} \mathrm{~b}$ & $1,32 \mathrm{~B} \mathrm{bc}$ \\
$10-20$ & $2,62 \mathrm{~A} \mathrm{~b}$ & $2,43 \mathrm{~A} \mathrm{~b}$ & $1,55 \mathrm{~B} \mathrm{~b}$ \\
$20-40$ & $3,81 \mathrm{~A} \mathrm{a}$ & $3,15 \mathrm{~B} \mathrm{a}$ & $2,44 \mathrm{C} \mathrm{a}$ \\
\hline
\end{tabular}

Médias com letras maiúsculas distintas, entre tratamentos, e minúsculas distintas, entre profundidades, diferem entre si (Duncan, 5\%).
Os teor es de potássio, cál cio e magnésio trocáveis nosol o (Quadro 3) foram mais baixos nos tratamentos com eucalipto. Este fato poderia ser explicado pela mai or absorção desses nutrientes pel o eucalipto, mas nãohouve diferença entre os tratamentos em relação à sua concentração notecido das plantas (Quadro 5). Portanto, é provável que os maiores teores dos nutrientes no sol o sob acácia simples sejam devidos à taxa de decomposição da serapilheira com relação $\mathrm{C}: \mathrm{N}$ mais estreita, que libera maior quantidade de nutrientes para o solo.

Vezzani et al. (1999) determinarama relação C:N da serapil heira dos três tratamentos, indi cando uma relação C:N menor para acácia simples (23) em relação ao consórcio (36) e ao eucal ipto simples (68). A serapilheira do consórcio, com relação C:N menor que a do eucal i pto simples, favoreceu a decomposição e liberação de nutrientes, ocorrendo maior acúmulo de cálcio e magnésio no solo com o consórcio em relação ao solo com eucalipto simples. A matéria orgânica contribui para a carga negativa total de superfície do solo (Raij, 1969) e o seu teor mais el evado no tratamento com acácia simples (Quadro 1) pode ter colaborado para a maior retenção de potássio, cálcio e magnésio no solo, diminuindo a lixiviação desses elementos. $O$ efeito da acácia na elevação dos teores de elementos no solo foi relatado por Vezzani et al. (1995), no Rio Grande do Sul, onde o cultivo de Acacia mearnsii por sete anos proporcionou aumento nos teores de fósforo, potássio e cál cio no sol o $(0-10 \mathrm{~cm})$, em relação ao campo nativo adjacente. Também Costa et al. (1996) demonstraram que o cultivo de Acacia mangium el evou os teores de fósforo e de potássio à profundidade de $0-10 \mathrm{~cm}$ de um Planossolo. No Havaí, os teores de potássio, cálcio e magnésio no solo com consórcio 1:1 de Al bi zia e eucalipto foram superiores no solo com povoamento de eucalipto simples (DeBell et al., 1989).

Em relação aos nutrientes no solo do tratamento de acácia simples comparados aos do eucalipto, a diferença foi suficiente para alterar a classe de fertilidade de $\mathrm{K}$ e Mg de médio para alto, segundo a CFSRS/SC (1994). Para os teores dos demais nutrientes no solo, este fato não foi observado.

Os teores de nitrogênio no solo foram menores em praticamentetodas as profundidades do sol o com eucalipto simples, quando comparados aos dos tratamentos com acácia (consórcio e acácia simples) (Quadro 4). O teor de nitrogênio no solo com o consórcio foi bastante similar ao determinado no tratamento com acácia simples, não havendo diferença significativa nas profundidades abaixo de $5 \mathrm{~cm}$. O maior teor de nitrogênio nos tratamentos com acácia deveu-se à fixação simbiótica de nitrogênio atmosférico pela leguminosa. Auer \& Silva (1992) relataram queAcácia mearnsii revel ou capacidade de fixar $200 \mathrm{~kg} \mathrm{ha}^{-1} \mathrm{ano}^{-1}$ de N. Além disso, a decomposição da serapilheira rica em 
Quadro 3. Teores de fósforo, potássio, cálcio e magnésio, na profundidade de 0-10 cm (médias de cinco épocas de amostragem e três repetições)

\begin{tabular}{lccc}
\hline \multicolumn{1}{c}{ Nutriente } & Eu x Ac & Eucalipto & Acácia \\
\hline $\mathrm{P}\left(\mathrm{mg} \mathrm{dm}^{-3}\right)$ & $4,9 \mathrm{~A}$ & $4,3 \mathrm{~A}$ & $4,7 \mathrm{~A}$ \\
$\mathrm{~K}\left(\mathrm{mg} \mathrm{dm}^{-3}\right)$ & $118 \mathrm{~B}$ & $112 \mathrm{~B}$ & $148 \mathrm{~A}$ \\
$\mathrm{Ca}\left(\mathrm{cmol}_{\mathrm{c}} \mathrm{dm}^{-3}\right)$ & $1,03 \mathrm{~B}$ & $0,69 \mathrm{C}$ & $1,83 \mathrm{~A}$ \\
$\mathrm{Mg}\left(\mathrm{cmol}_{\mathrm{c}} \mathrm{dm}^{-3}\right)$ & $0,82 \mathrm{~B}$ & $0,62 \mathrm{C}$ & $1,12 \mathrm{~A}$
\end{tabular}

Médias com letras distintas, na linha, diferem entre si (Duncan, $5 \%$.

Quadro 4. Teores de nitrogênio total no solo (médias de cinco épocas de amostragem e três repetições)

\begin{tabular}{cccc}
\hline Profundidade & Eu $\times$ Ac & Eucalipto & Acácia \\
\hline $\mathrm{cm}$ & & $\mathrm{mg} \mathrm{dm}^{-3}$ & \\
\cline { 2 - 4 } & & & \\
$5-10$ & $1,83 \mathrm{Ba}$ & $1,50 \mathrm{Ca}$ & $1,97 \mathrm{Aa}$ \\
$10-20$ & $1,41 \mathrm{Ab}$ & $1,25 \mathrm{Bb}$ & $1,46 \mathrm{Ab}$ \\
$20-40$ & $1,26 \mathrm{Ac}$ & $1,13 \mathrm{Abc}$ & $1,27 \mathrm{Ac}$ \\
& $1,25 \mathrm{Ac}$ & $1,05 \mathrm{Bc}$ & $1,13 \mathrm{ABd}$
\end{tabular}

Médias com letras maiúsculas distintas, entre tratamentos, e minúsculas distintas, entre profundidades, diferem entre si (Duncan, 5\%).

Quadro 5 Quantidade de nutrientes nas folhas e galhos de eucalipto e de acácia, aos 45 meses do plantio (médias de três repetições)

\begin{tabular}{|c|c|c|c|c|c|}
\hline Sistema de cultivo & $\mathbf{N}$ & $\mathbf{P}$ & $\mathbf{K}$ & $\mathrm{Ca}$ & Mg \\
\hline & \multicolumn{5}{|c|}{ g planta-1 } \\
\hline Eucalipto consorciado & 96 & 7,5 & 73 & 60 & 20 \\
\hline Eucalipto puro & 79 & 7,6 & 82 & 66 & 17 \\
\hline Acácia consorciada & 112 & 5,0 & 71 & 56 & 18 \\
\hline Acácia pura & 137 & 6,0 & 79 & 72 & 22 \\
\hline
\end{tabular}

Médias não diferem entre sistemas de cultivo (Duncan, 5\%).

nitrogênio foi favorecida nos tratamentos com acácia (consórcio e acácia simples), pela menor relação C:N encontrada. Com isto, a ciclagem biogeoquímica de nitrogênio foi mais eficiente, promovendo aumento nos teores do nutriente no solo.

Vezzani et al. (1995) verificaram aumento nos teores de nitrogênio total do solo $(0-10 \mathrm{~cm})$ com o cultivo de Acacia mearnsii no Rio Grande do Sul. No Havaí, plantios consorciados de Albizia e eucalipto em várias proporções, com 48 meses de idade, apresentaram teor de nitrogêniototal no solo
$(0-20 \mathrm{~cm})$ significativamente maior $(0,55$ a $0,64 \%)$ do que o plantio de eucalipto simples e fertilizado com um adicional de $160 \mathrm{~kg} \mathrm{ha}^{-1}$ de $\mathrm{N}(0,51 \%)$ (DeBell et al., 1989).

\section{Características das plantas}

A principal influência da acácia no consórcio para as plantas de eucalipto foi em relação ao nitrogênio, graças à maior disponibilidade desse elemento nos primeiros centímetros do solo. Apesar de não apresentar diferença estatística entre os sistemas de cultivo, o eucalipto consorciado alocou $17 \mathrm{~g}$ de nitrogênio por planta a mais do que quando cultivado simples, representando uma diferença de $22 \%$. Por outrolado, fol has egal hos deacácia nocul tivo simples acumularam $18 \%$ denitrogênioa mais do quea acácia consorciada, significando que o eucalipto absorveu nitrogênio em detrimento da absorção pela acácia (Quadro 5). Assim, a acácia favoreceu o eucalipto, no sistema em consórcio, no quetange ao nitrogênio.

A quantidade de nitrogênio acumulada nas fol has e gal hos das plantas de acácia eeucal ipto, no sistema em consórcio, representa o equivalente a $173 \mathrm{~kg} \mathrm{ha}^{-1}$, enquanto o eucalipto simples acumulou somente $131 \mathrm{~kg} \mathrm{ha}^{-1}, 24 \%$ a menos. Este maior acúmulo de nitrogênio nas fol has e gal hos no consórcio evidencia o benefício do consórcio eucalipto x acácia para o enriquecimento do ecossistema em nitrogênio, el evando o potencial de produtividade. O nitrogênio das fol has e dos galhos representa uma porção de ciclagem relativamente rápida, em comparação com o da madeira e da casca, e, ainda, com a vantagem de permanecer na área quando a floresta é col hida. No caso do consórcio, a maior riqueza em nitrogênio dos resíduos da col heita florestal (fol has, galhos e casca) faz com que a sua decomposição seja mais rápida, por favorecer a atividade dos microrganismos decompositores.

As quantidades totais acumuladas de fósforo, potássio, cál cio e magnésio no tecido das plantas de eucali pto e de acácia não diferiram estatisticamente entre os sistemas de cultivo (Quadro 5). Da mesma forma, o crescimento das plantas de eucalipto, medido pelo DAP e pela altura das árvores (Quadro 6), não diferiu estatisticamente entre os sistemas de cultivo. E mbora o eucal ipto consorciado tenha sido favorecido pelo maior suprimento de nitrogênio da acácia, esta maior disponibilidade não acarretou maior crescimento das plantas.

A resposta em crescimento também é uma conseqüência de outros fatores que interagem no consórcio, reduzindo a competi ção e facilitando o desenvolvimento da floresta. Binkley et al. (1992), analisando consórcio deE ucal yptus saligna eAl bizia fal cataria, verificaram que, quando a proporção de al bizia abrangeu um terço ou mais do povoamento, a competição entre espécies pareceu ser menos crítica, indicando que as espécies apresentaram diferentes demandas sobre os recursos do meio. 
Quadro 6. Diâmetro à altura do peito (DAP) ealtura de árvores de eucalipto e de acácia, aos 45 meses do plantio (médias de três repetições)

\begin{tabular}{lcc}
\hline Sistema de cultivo & DAP & Altura \\
\hline & $\mathrm{cm}$ & $\mathrm{m}$ \\
Eucalipto consorciado & 13,2 & 15,7 \\
Eucalipto puro & 12,4 & 15,1 \\
Acácia consorciada & 10,9 & 14,0 \\
Acácia pura & 11,1 & 13,6 \\
\hline
\end{tabular}

Médias não diferem entre sistemas de cultivo (Duncan, 5\%).

A produção de fol has e gal hos, tanto de eucal ipto quanto de acácia, não foi afetada pelo consórcio (Quadro 7), demonstrando que não houve al teração no desenvol vimento das plantas.

\section{Produção de madeira no consórcio}

O volumetotal demadeira produzido peloconsórcio não diferiu do produzido pelo eucalipto simples (Quadro 8). No consórcio, o eucal ipto contribuiu com $64 \%$ do volume total de madeira, apesar de ter a metade do número de plantas do cultivo si mples. Os valores de DAP e altura do eucalipto no consórcio (Quadro 6) mostram a vantagem das árvores desta espécie em competição interespecífica. Alguns trabalhos registraram maior produtividade do eucalipto em consórcio com árvores leguminosas. DeBell et al. (1985) verificaram que a produção média de peso da matéria seca em cultivo simples de eucalipto com 5,5 anos foi de $38.000 \mathrm{~kg} \mathrm{ha}^{-1}$, enquanto em consórcio com acácia esta produção foi de 52.000 e em consórcio com albizia de 95.000.

\section{Quadro 7. Produção de fol has e gal hos de eucalipto e de acácia, aos 45 meses do plantio (médias de três repetições)}

\begin{tabular}{lrr} 
& Consórcio & Puro \\
\hline & \multicolumn{2}{c}{ kg planta-1 $^{-1}$} \\
\cline { 2 - 3 } & \multicolumn{3}{c}{ E ucalipto } \\
Folhas & 4,1 & 3,7 \\
Galhos & 10,7 & 9,1 \\
Total & 14,8 & 12,8 \\
& & \\
& & Acácia \\
Folhas & 2,7 & 3,7 \\
Galhos & 8,8 & 8,9 \\
Total & 11,5 & 12,6 \\
\hline & & \\
\hline Médias não diferem entre sistemas de cultivo (Duncan, 5\%).
\end{tabular}

Quadro 8. Volume de madeira, aos 45 meses do plantio (médias de três repetições)

\begin{tabular}{ccc}
\hline Tratamento & Componente & Volume \\
\hline \multirow{3}{*}{ Eux Ac } & Acácia & $\mathrm{m}^{3} \mathrm{ha}^{-1}$ \\
& Eucalipto & 39 \\
& Total & 71 \\
Eucalipto & & $110 \mathrm{a}$ \\
Acácia & & $109 \mathrm{a}$ \\
& & $78 \mathrm{~b}$
\end{tabular}

Médias com letras distintas, na col una, diferem entresi (Duncan, $5 \%)$.

A biomassa total de um consórcio com quatro anos de Eucalyptus saligna e Albizia falcataria que continha mais que $34 \%$ de al bizia excedeu a produção de eucalipto simples (DeBell et al., 1989). Aos seis anos, o consórci o com 34\% de eucal ipto e 66 de al bizia apresentou biomassa de $174.000 \mathrm{~kg} \mathrm{ha}^{-1}$, enquanto o eucalipto simples e fertilizado, biomassa de $148.000 \mathrm{~kg} \mathrm{ha}^{-1}$ (Binkley et al., 1992).

\section{CONCLUSÕES}

1. O consórcio beneficiou a nutrição do eucal ipto, em relação ao nitrogênio.

2. O estoque de nitrogênio no ecossistema aumentou com o consórcio, comparado ao do cultivo simples de eucalipto.

3. A produção total de madeira foi a mesma no consórcio e no cultivo simples de eucalipto, embora o eucalipto tenha contribuído com $64 \%$ da produção do consórcio.

\section{AGRADECIMENTOS}

Agradecemos à empresa de Celulose e Papel Riocell S.A, pela permissão e auxílio na realização destetrabalho.

\section{LITE RATURA CITADA}

AUER, C.G. \& SILVA, R. Fixação de nitrogênio em espécies arbóreas. In: CARDOSO, E.J .B.N.; TSAI, S.M. \& NEVES, M.C.P. Coords. Microbiologia do solo. Campinas, Sociedade Brasileira de Ciência do Solo, 1992. p.157-172.

BINKLEY, D.; DUNKIN, K.A.; DEBELL, D. \& RYAN, M.G. Production and nutrient cycling in mixed plantations of eucalyptus and al bizia in Hawaii. For. Sci., 38:393-408, 1992. 
COMISSÃO DE FERTILIDADE DO SOLO - CFSRS/SC. Recomendações de adubação e de calagem para os estados do Rio Grande do Sul e de Santa Catarina. 3 ed. Passo Fundo, Sociedade Brasileira de Ciência do Solo/Núcleo Regional Sul, 1994. 224p.

COSTA, G.S.; ANDRADE, A.G. \& FARIA, S.M. Ciclagem de nutrientes em um plantio deAcacia mangium com seis anos de idade. In: SOLO SUELO - CONGRESSO LATINO AMERICANO DE CIÊNCIA DO SOLO, 13., Águas de Lindóia, 1996. Resumos Expandidos. Águas de Lindóia, Sociedade Brasileira de Ciência do Solo, 1996. (CD-ROM)

DeBELL, D.S.; WHITESELL, C.D. \& SCHUBERT, T.H. Mixed plantations of Eucalyptus and leguminous trees enhance biomass production. Berkeley, USDA, Pacific Southwest Forest and Range Experiment Station, 1985. 6p. (Res. Paper PSW, 175)

DeBELL, D.S.; WHITESELL, C.D. \& CRABB, T.B. Benefits of Eucalyptus-Al bizia mixtures vary by site on Hawaii I sland. Berkeley, USDA, Pacific Southwest Forest and Range Experiment Station, 1987. 6p. (Res. Paper PSW, 187)

DeBELL, D.S.; WHITESELL, C.D. \& SCHUBERT, T.H. Using $\mathrm{N}_{2}$-fixing Albizia to increase growth of Eucalyptus plantations in Hawaii. For. Sci., 35:64-75, 1989.

DeBELL, D.S. \& HARRINGTON, C.A. Deployng genotypes in short-rotation plantations mixtures and pure cultures of clones and species. For. Chron., 69:705-713, 1993.
FINGER, C.A.G. Fundamentos de biometria florestal. Santa Maria, Universidade Federal de Santa Maria, 1992. 269p.

NOVAIS, R.F.; BARROS, N.F \& \& NEVES, J .C.L. Nutrição mineral do eucalipto. In: BARROS, N.F . \& NOVAIS, R.F., eds. Relação solo-eucalipto. Viçosa, Folha de Viçosa, 1990. p.25-98.

RAIJ , B. van. A capacidade detroca de cátions das frações orgânica e mineral em solos. Bragantia, 28:85-112, 1969.

SALET, R.L. Toxidez dealumínio no sistema plantio direto. Porto Alegre, Faculdade de Agronomia da Universidade Federal do Rio Grande do Sul, 1998. 109p. (Tese de Doutorado)

TEDESCO, M.J .; GIANELLO, C.; BISSANI, C.A.; BOHNEN, H. \& VOLKWEISS, S.J. Análise de solo, plantas e outros materiais. 2.ed. Porto Alegre, Universidade F ederal do Rio Grande do Sul, 1995. 174p. (Boletim Técnico de Solos, 5)

VEZZANI, F.M.; BARROS, N.F.; NOVAIS, R.F. \& BORTOLÁS, E.P. Influência do solo e do consórcio com acácia negra no crescimento e composição mineral de eucalipto. In: CONGRESSO BRASILEIRO DE CIÊNCIA DO SOLO, 25., Viçosa, 1995. Resumos Expandidos. Viçosa, Sociedade Brasileira de Ciência do Solo, 1995. p.890-892.

VEZZANI, F.M.; BARROS, N.F . \& TEDESCO, M.J . Decomposição e liberação de nutrientes da serapilheira de eucalipto e acácia negra. R. Ci. UNICRUZ, 1:27-32, 1999. 
F. M.VEZZANI et al.

R. Bras. Ci. Solo, 25:225-231, 2001 